\title{
NAS ASAS DAS CIÊNCIAS: O ICC NO CAMPUS DA UNB*
}

Christine Ramos Mabler

A presente discussão trata da análise histórica e espacial do Instituto Central de Ciências, bem como do seu papel articulador de urbanidade no campus da Universidade de Brasília. Esse edifício é um representante emblemático da arquitetura institucional no conjunto da produção moderna brasileira, tendo sido explorado enquanto objeto de pesquisa sob vários aspectos, inclusive quanto à afiliação de sua linguagem ao brutalismo. Para além de suas qualidades e características intrínsecas e para subsidiar a observação sobre seu protagonismo no complexo da UnB é importante resgatar algumas questões seminais acerca do modelo em questão: o campus universitário, no qual está inserido. A esse propósito, vale recuperar a gênese do termo:

Inventado na Princeton colonial como um latinismo, talvez em alusão ao Campus Martius de Roma antiga, campus expressou perfeitamente o espaço aberto, ambiente semi-rural do College de New Jersey e as qualidades físicas que iriam caracterizar tantas escolas americanas (TURNER, 1995, p. 47).

Esse conceito foi cunhado no contexto norte-americano do século XVII, quando as universidades pioneiras foram embriões da ocupação territorial, impulsionando seu desenvolvimento por meio da educação. Ainda que o resultado dessas concepções tenha sido bastante diversificado e largamente exportado, suscitando múltiplas discussões, o que se traz para a presente análise é que a maior parte dessas soluções tem em comum a constituição de um conjunto, cujos componentes são numerosos edifícios, geralmente pavilhões, inseridos em um vasto espaço, conformando uma academical village (TURNER, 1995). Em outras palavras, um microcosmo urbano ou uma "cidade acadêmica", articulando edificações simbólicas e acadêmicas e promovendo suas relações com os espaços não construídos, predominantemente naturais, resultando em uma ambiência adequada à imersão e ao convívio intenso de seus usuários, apesar de seu isolamento e das críticas decorrentes a esse atributo. Dessa ambiência resulta o próprio termo latino campus, ou campo.

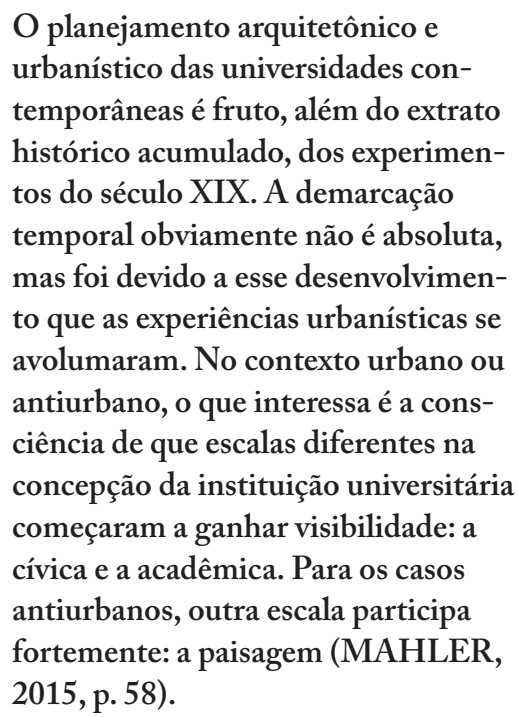

E dessa vertente, mesclada às soluções europeias de bairros e cidades universitárias, ou seja, espaços imersos em contextos urbanos, encontra-se a matriz - híbrida - de grande parte dos campi *Versão ampliada de trabalho apre-
sentado no $10^{\circ}$ Seminário DOCO-
MOMO Brasil, Curitiba, 2013. 
146

${ }^{1}$ Fundada em 15 de dezembro de 1961, mediante lei no 3.998, com Estatuto aprovado pelo Decreto $n^{\circ}$ 500, homologado em 15 de janeiro de 1962 (www.unb.br). brasileiros, dentre os quais o campus em questão, denominado Darcy Ribeiro. A respeito da ideologia por trás da localização das universidades brasileiras apartadas das cidades, Almeida (1983) aponta:

Verificou-se que a existência do campus, implantado na periferia das cidades e em extensas áreas acima de 300 hectares e concebido como minicidades, cria problema de ordem física para integração de áreas de conhecimento, bem como para sua inserção no espaço urbano. Esse modelo físico deve sua existência, em parte à história jesuíta, ao ideário político, econômico e institucional dos administradores, à peculiaridade da autonomia universitária e à ideologia presente na Lei da Reforma do Ensino Superior (Lei n. 5.540/68), entre outros condicionantes de menor importância (ALMEIDA, 1983, p.7).

Assim, a estratégia dos modelos de campi brasileiros foi inserida no jogo complexo de variáveis urbanas nos âmbitos político, ideológico, econômico e cultural, tendo benefícios e problemas dela decorrentes. Segundo Almeida (1983, p. 55) "somente em 1962 ocorreu um fato novo na implantação da universidade brasileira com a organização e construção da Universidade de Brasília (UnB), na Capital Federal. Esta universidade serviu, posteriormente, de modelo orientador da Lei de Reforma do Ensino Superior (Lei n. 5.540/68)".

A abordagem acerca do período de criação da UnB remete, ainda, às razões desenvolvimentistas específicas que nortearam a construção de Brasília. Antes mesmo dos primeiros gestos para o desenho do ICC serem produzidos, as oportunidades de construção da nova Capital e, em seguida, a criação da instituição, já acenavam para a necessidade de se pensar em um edifício absolutamente inovador.

Ao contrário de outras universidades, a UnB não nasce marcada pela tradição, com a aglutinação de centenárias instituições de ensino pré-existentes. No contexto de Brasília, a instituição nasce na binterland, compromissada com a construção de novos desafios materiais e intelectuais. Nasce, ainda, com a grande responsabilidade de interiorizar a educação, servindo de modelo às demais instituições federais.
A Universidade de Brasilia foi funda- da no mesmo ano que a nova capital federal do país, em 1960, graças a iniciativas do polêmico antropólogo Darcy Ribeiro. Sua concepção de vanguarda trouxe inúmeras inovações para o ensino superior, tanto de orga- nização - como a adoção da estrutura departamental e do sistema de cré- ditos para avaliação do rendimento escolar, quanto de fundo - como a extinção do regime de cátedra e a ênfase na pesquisa e na produção de conhecimentos (FICHER, 2001).

A UnB foi criada como uma fundação, com autonomia para administrar seus órgãos e recursos ${ }^{1}$, através de uma estrutura integrada, composta pelos Institutos Centrais, Faculdades Profissionais e Órgãos Complementares, "tendo como 
premissa o humanismo, a livre criação cultural e a integração da ciência e tecnologia, como motores de transformação da sociedade" (RODRIGUEZ, 2007, p. 13). Sua proposta de estrutura departamental introduziu a pós-graduação e o currículo flexível, e dividiu a formação em dois ciclos: dois anos para o ensino "fundamental" e o e três anos para o "profissional".

No plano urbanístico para a $\mathrm{UnB}, \mathrm{Lu}^{-}$ cio Costa propôs um desdobramento de seu projeto para o Plano Piloto da cidade, definindo o espaço universitário como um vasto parque, aberto à população, com vegetação nativa. Ficou determinada a localização da gleba de cerca de 260 hectares para a construção da universidade, a exemplo dos projetos de escolas americanas, com a influência do urbanismo pitoresco ${ }^{2}$, para o qual era fundamental fundir a universidade à paisagem e nela distribuir os espaços construídos.

O campus foi concebido com rígida setorização das atividades acadêmicas por áreas de conhecimento, separação da circulação de pedestres e de veículos e isolamento dos setores esportivo e habitacional por extensas áreas livres (GOROVITZ, 1993, p. 61 e 63).
Alterações no partido de Brasília acarretaram mudanças para a universidade, que foi afastada em alguns quilômetros da área inicialmente estabelecida, distanciando-se da cidade e situando-se na borda nordeste do Lago Paranoá entre o lago e a Asa Norte. A setorização do campus ocorre com o acesso principal pela via L4 Norte, às margens do lago e passa a "dar as costas" para a cidade.

A proposta para o campus da UnB corresponde aos conceitos modernistas arquitetônicos e urbanísticos, e também à nova filosofia educacional, na qual Anísio Teixeira e Darcy Ribeiro foram protagonistas, com a proposição pedagógica do ensino sistêmico para a nova instituição. As edificações previstas no plano não estabelecem vínculo aparente com a malha viária do campus, possuindo implantações livres. Os espaços abertos são grandes vazios sem hierarquia, resultando em um espaço bastante homogêneo (CASTOR, 2004). O território foi dividido em grandes parcelas, delimitado por vias que formam as quadras internas, com edificações distribuídas de maneira dispersa. Uma área central, margeada pelo acesso principal, foi destinada aos

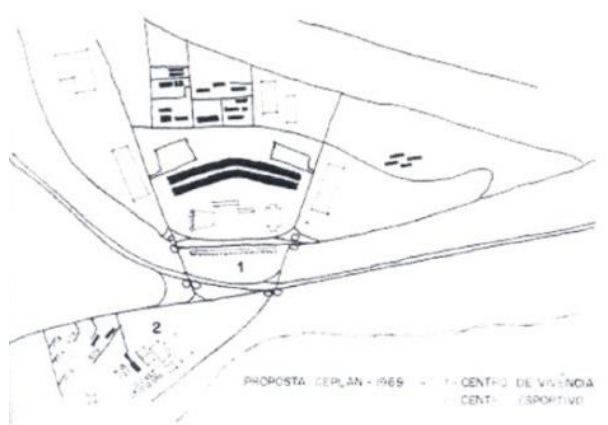

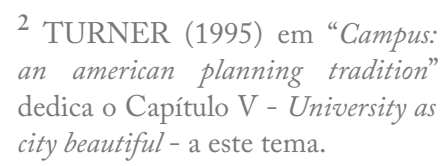
city beautiful - a este tema.

Figura 1 - Estudo urbanístico de 1969. Fonte: CEPLAN, 1972. In RODRIGUEZ, 2007. 

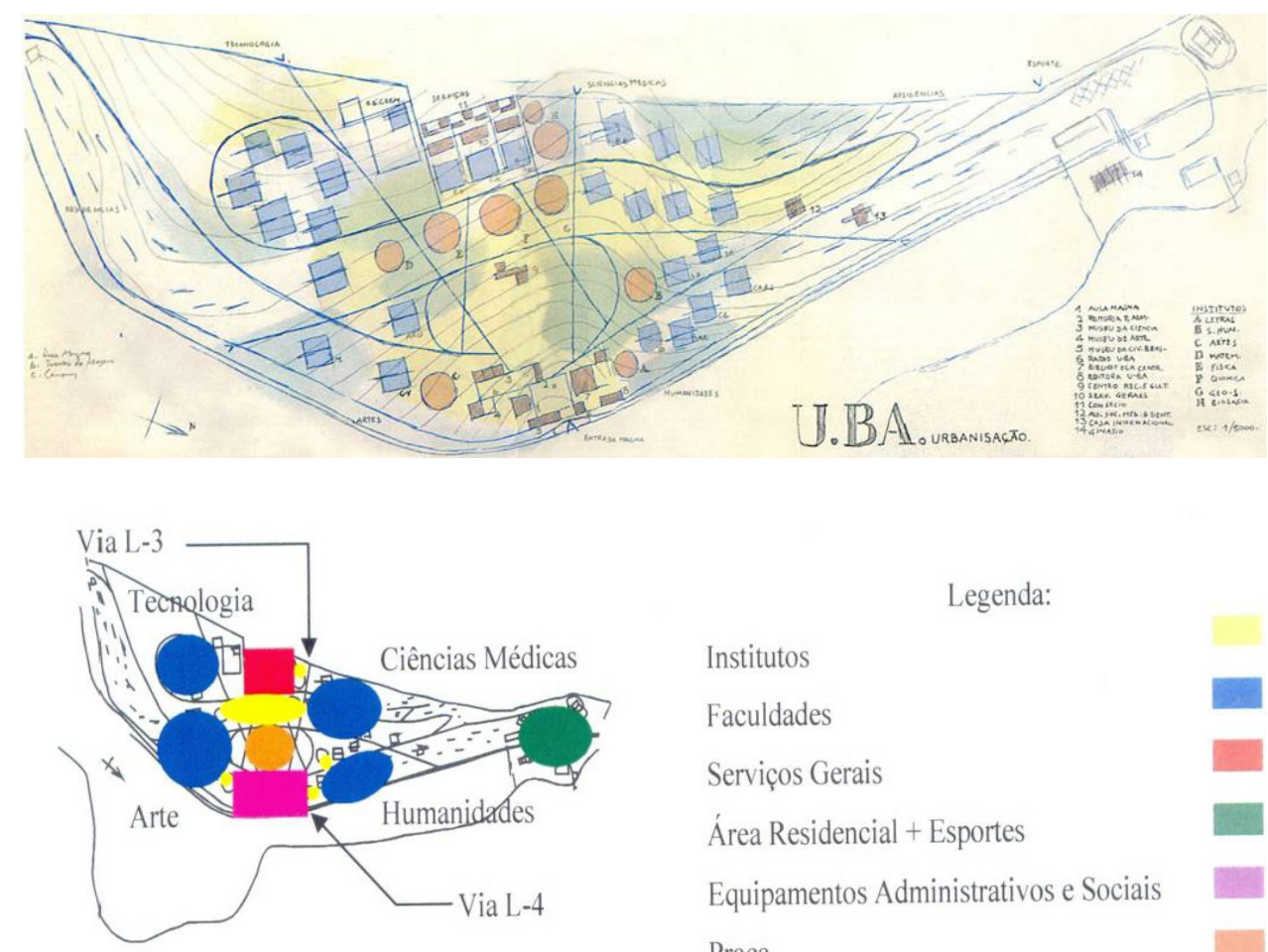

edifícios simbólicos, de interesse comum, tais como Reitoria, Biblioteca e Museu Universitário (RODRIGUEZ, 2007).

O edifício do Instituto Central de Ciências (ICC) é um exemplar emblemático da arquitetura produzida na década de 1960 (1963-1971). A obra, de autoria de Niemeyer contou com a colaboração de João da Gama Filgueiras Lima.

O projeto de Oscar Niemeyer corresponde à unificação dos cinco Institutos de Ciências (Matemática, Física, Química, Biologia e Geociências) previstos por Darcy Ribeiro no projeto da universidade e por Lucio Costa no primeiro plano urbanístico da UnB. A decisão de unificar os

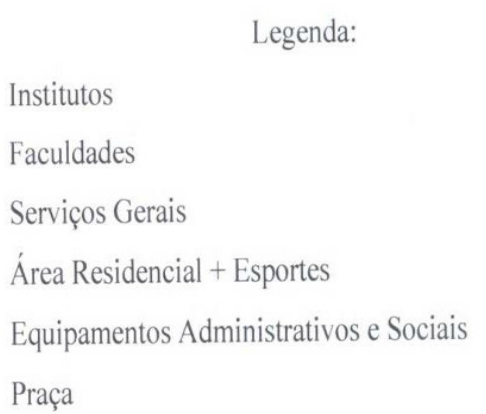

institutos partiu do próprio Niemeyer (SCHLEE, 2014, p. 50).

Para Ficher (2001) “O ICC é um daqueles exemplos de edifícios cuja realização se confunde com a história da instituição a que pertence e que passa a representá-la, reforçando sua identidade e alterando os hábitos de seus usuários”. O icônico projeto faz parte das modificações propostas por Oscar Niemeyer, no segundo plano urbanístico desenvolvido para a $\mathrm{UnB}$, quando este assume a diretoria do CEPLAN (1962-64). A proposta deveria contemplar um programa complexo, que incluía instalações administrativas, salas de aulas, auditórios, além de uma vasta gama de laborató- 
rios científicos, e responder a exigências díspares quanto a áreas e alturas. Sua estrutura imponente foi idealizada para agregar valores à concepção de uma universidade moderna.

O edifício é composto por uma parte central e curva e duas alas lineares e periféricas, a exemplo das asas do Plano Piloto, situado em uma faixa de terreno acima da Praça Maior "que mediante sua concavidade e construção em arco define o espaço da praça, como elemento estruturador do campus da UnB" (RODRIGUEZ, 2007).

O ICC - ou Minhocão, como é conhecido - começou a ser construído em 1963, pela extremidade sul, logo depois dos prédios de Serviços Gerais e da Faculdade de Educação. No entanto, em 1969, apenas 15\% da obra havia sido concluída. Ainda naquele período foram feitas modificações no projeto, sendo que a principal delas foi o aumento do espaço de ocupação, proposto pela construtora Rabello S.A., após a escavação de uma grande área de subsolo. [...] Quando da execução da obra, o bloco leste também ganhou um nível em subsolo, destinado às unidades de suprimento (depósitos), acessíveis por meio das escadas e por uma rua interna de serviço, que percorre o edifício de ponta a ponta. Tal distribuição funcional foi pensada no sentido de garantir ao prédio uma ocupação transversal flexível, ou seja, cada um dos institutos seria contemplado com espaços didáticos variados e programaticamente complementares, localizados em ambas as alas, e ainda contando com a porção central livre (hoje ajardinada) como possibilidade de expansão. [...] No entanto a ocupação do ICC ocorreu de forma contrária (longitudinal), e cada unidade ocupou parte de uma determinada ala, privando-se de alguns

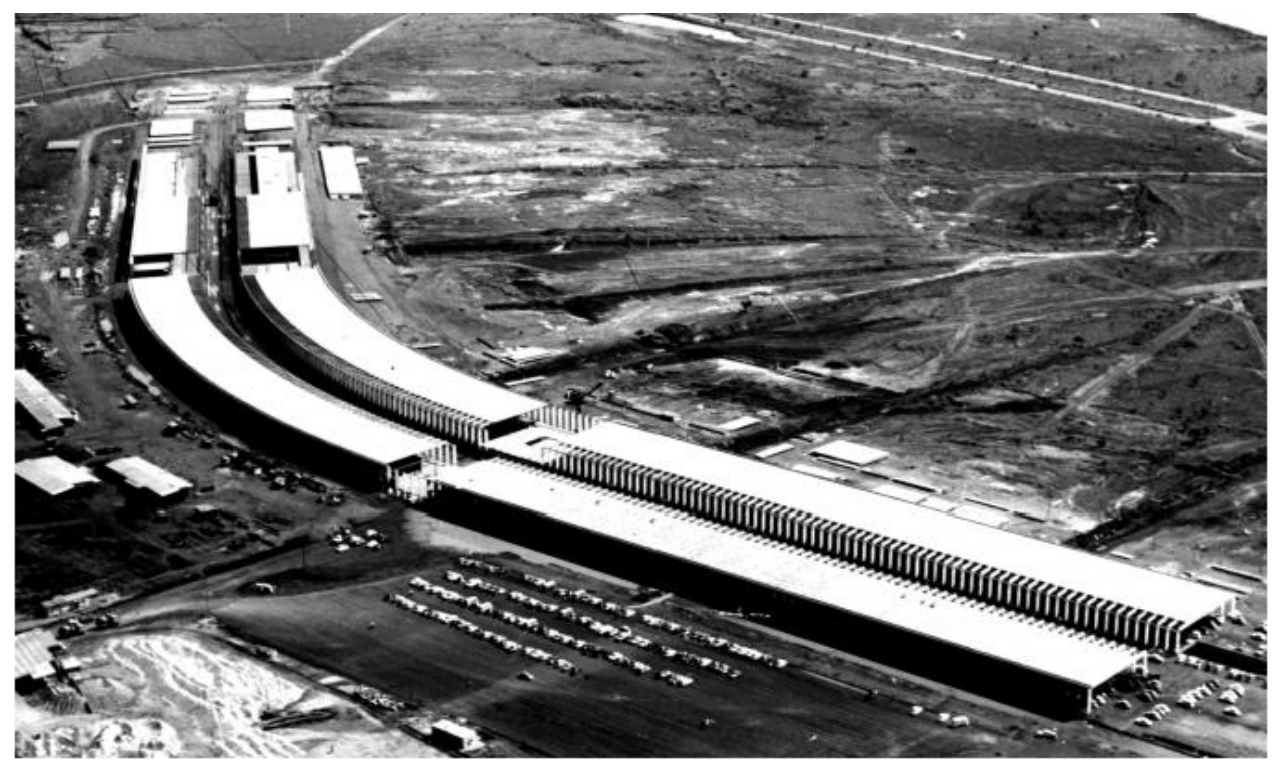

Figura 4 - Foto aérea do ICC e do campus em construção. Fonte: UnB Agência - www.unb.br. 


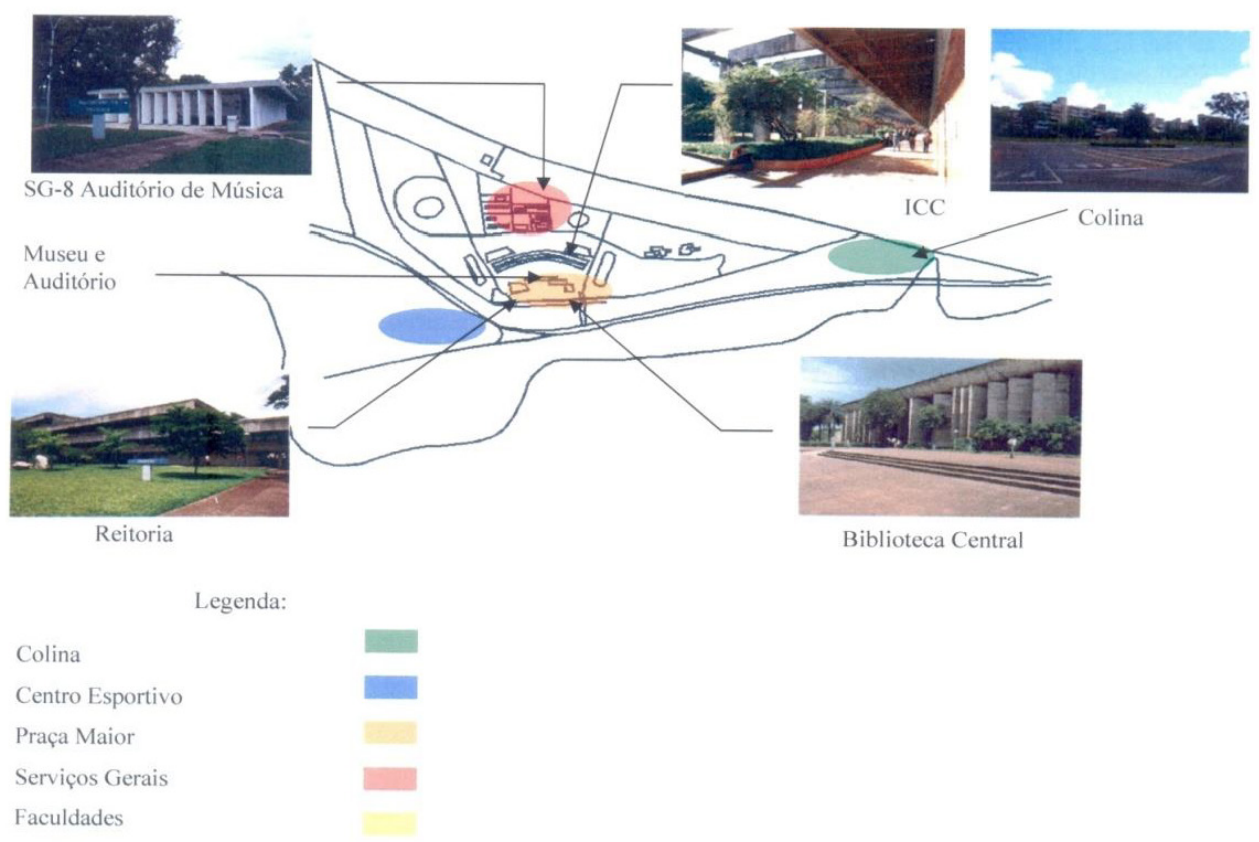

espaços fundamentais para o exercício pleno de suas atividades. Ainda fruto de um processo de ocupação acelerado e, muitas vezes, descontrolado, os subsolos passaram a ser utilizados para outros fins, não previstos no projeto original (SCHLEE, 2014, p. 50-52). 7

O ICC, somado aos edifícios de seu entorno e à praça, define uma centralidade fundamental para o campus, resultando em uma região densamente utilizada no cotidiano da universidade. A proposta integradora do ICC é responsável pela diversidade de funções e espaços que abriga sob suas alas, numa interpretação inovadora de Niemeyer sobre uma proposta sistêmica de partido arquitetônico para a universidade.
No sentido transversal leste-oeste, o interior foi organizado em duas alas separadas por uma faixa de $15 \mathrm{~m}$ de largura - hoje ocupada, no térreo, pela circulação de pedestres e por jardins e, no subsolo, por laboratórios e por uma via interna para veículos, que dá acesso a todos os pontos do edifício. O ICC nasceu para ser um edifício instrumental, parte da vida cotidiana dos estudantes. Poderia, por essa definição, ser um dos tantos objetos da paisagem do campus. Mas, ao invés disso, sua presença estrutura e organiza os fluxos inscritos na universidade, devido à proporção do edifício como um sistema espacial e aos diversos usos que abriga.

As alas têm larguras diferentes e foram concebidas com o objetivo de 
abrigar tipos diferentes de atividades. $\mathrm{Na}$ ala oeste, com 30 metros de largura, ficariam as atividades mais voltadas para o ensino, como sala de aulas e auditórios. $E$ na ala leste, com 25 metros de largura, seriam instalados predominantemente laboratórios científicos, cujas especificações não pudessem ser subordinadas a esses espaços padronizados deveriam ser instalados na faixa central, tendo como cobertura cúpulas de concreto armado, de modo a garantir pés-direitos adequados a suas necessidades Na prática, tal ocupação e especialização não foi obedecida $e$ espaços bem diferentes são usados atualmente para fins semelhantes. Unificado o conjunto, a estrutura do ICC é composta por grandes pórticos de concreto protendido, que se repetem a cada 3 metros por toda a extensão do prédio, e representam, de fato, mais de $70 \%$ do volume da construção." (FICHER, 2001)
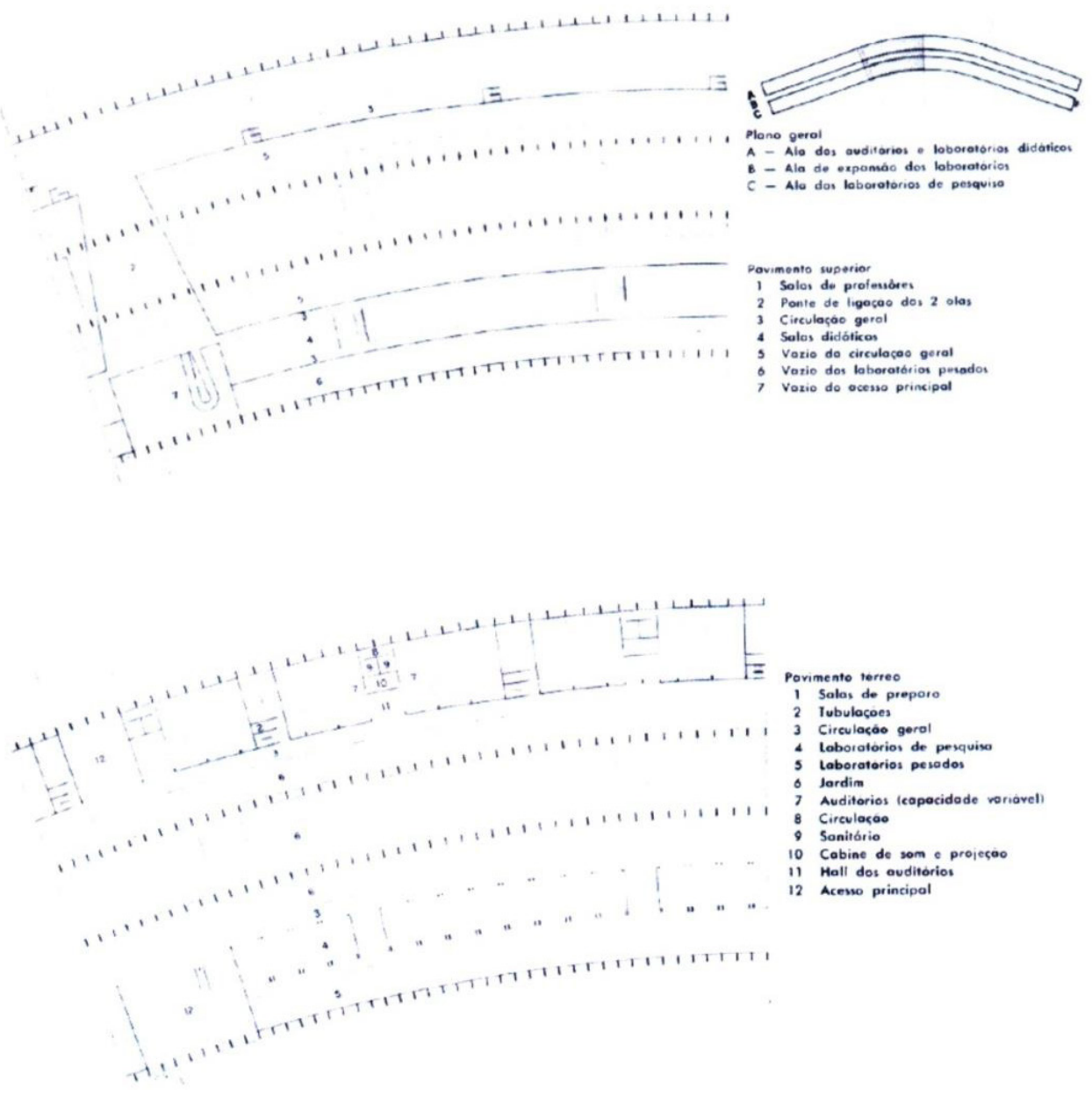

Figura 6 - Planta Baixa pavimento superior ICC. Fonte: Acrópole, 1970.

Figura 7 - Planta Baixa pavimento térreo ICC. Fonte: Acrópole, 1970. 
${ }^{3}$ Universidade de Bochum (1962), Universidade de Toulouse-le_Mirail (1966-68), ETH Zurich (1967), Universidade Bou-Ali-Sina, Hamadan (1977), dentre outras (KIEM, 2004).
Outro aspecto para a reflexão acerca do ICC é a abordagem do seu sistema construtivo. Nesse âmbito, trata-se, também, de um modelo inovador por sua produção em prefabricação. Sua realização é uma referência em premoldagem em grande escala in loco. Essa tecnologia potencializa as características brutalistas no ritmo ao longo do edifício. Além de sua proporção em si mesma, a repetição de pórticos que se sucedem a cada 3 metros, em sua extensão em concreto aparente e seu acabamento (ou, melhor dizendo, a falta dele) são características importantes do seu projeto. $\mathrm{O}$ resultado proposto the confere o status de um dos mais marcantes edifícios no panorama de universidades brasileiras, cuja configuração remete e contribui para a identidade do campus da UnB, carinhosamente denominado "Minhocão".

\section{A partir de 1970 a UnB tomou no- vos rumos. $\mathrm{O}$ seu plano urbanístico foi reelaborado. A Praça Maior foi rebatizada como Praça Central. Um Centro de Vivência (de Pedro Paulo Saraiva) foi acrescido ao conjunto e os edifícios da Biblioteca Central (de José Galbinski e Miguel Pereira) e da Reitoria (de Paulo Zimbres) foram executados. Foi também projetado outro complexo de Aula-Magna e Museu (de Matheus Gorovitz). Rei- toria e Biblioteca já funcionavam em 1975 (SCHLEE, 2011).}

No plano tridimensional, podemos observar a ambiguidade da presença do edifício do ICC em função da implantação predominantemente horizontal e da curvatura que dilui sua presença na percepção externa. O Minhocão participa com suavidade e elegância da paisagem do campus, apesar de sua tipologia em proporção de megaestrutura linear.

As grandes obras surgem a reboque de grandes narrativas politicas e econômicas, e esse fenômeno pode ser observado, contemporaneamente ao ICC, no pós-guerra na Europa. Essa tendência de projetos sistêmicos em universidades com grandes estruturas monolíticas viria a ser difundido na década de 1970, com o projeto alemão da Universidade Livre de Berlim (FUB), um mat-building, de autoria de Georges Candilis, Alexy Josic e Shadrach Woods, com Jonathan Greig e Manfred Schiedhelm como colaboradores (KIEM, 2008, p. 26).

Segundo Kiem,

O conceito adotado também pode ser colocado em relação aos esforços da vanguarda arquitetônica. No final dos anos 1950 havia o desejo de eliminar rígidas fronteiras entre a cidade $\mathrm{e}$ a casa, como também abordar a noção de crescimento e adaptabilidade nas estruturas em grande escala, que não eram limitadas a lugares e contextos específicos. Tais estruturas correspondiam à uma sociedade que se encontrava passando por uma mudança rápida. A proposta para Berlim não era apenas de um edifício universitário, mas para uma cidade ideal (KIEM, 2008, p. 14).

Essas observações acerca de universidades (estrangeiras) ${ }^{3}$ em projetos sistêmicos, sobretudo em sistemas de tramas, 

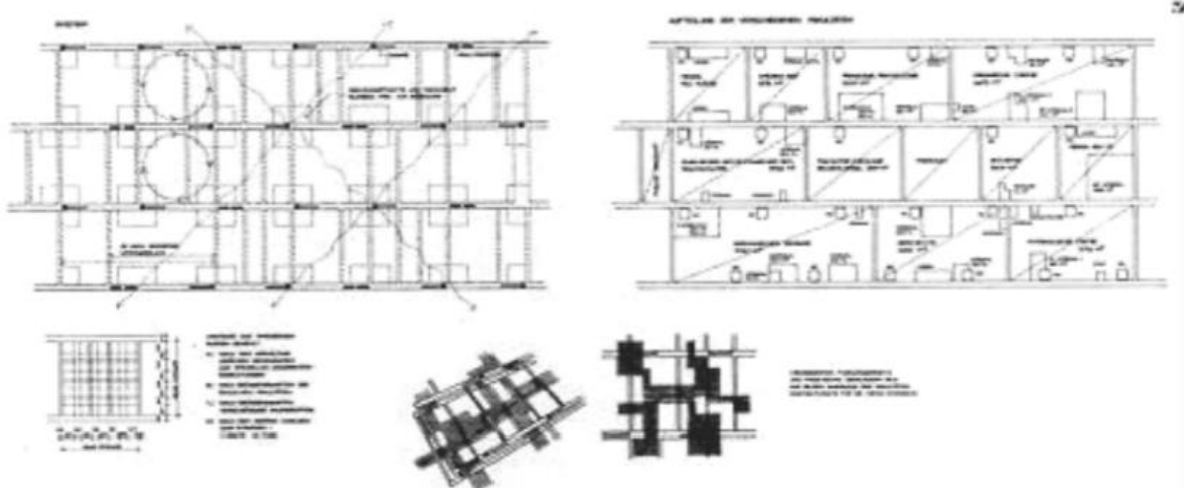
포로.
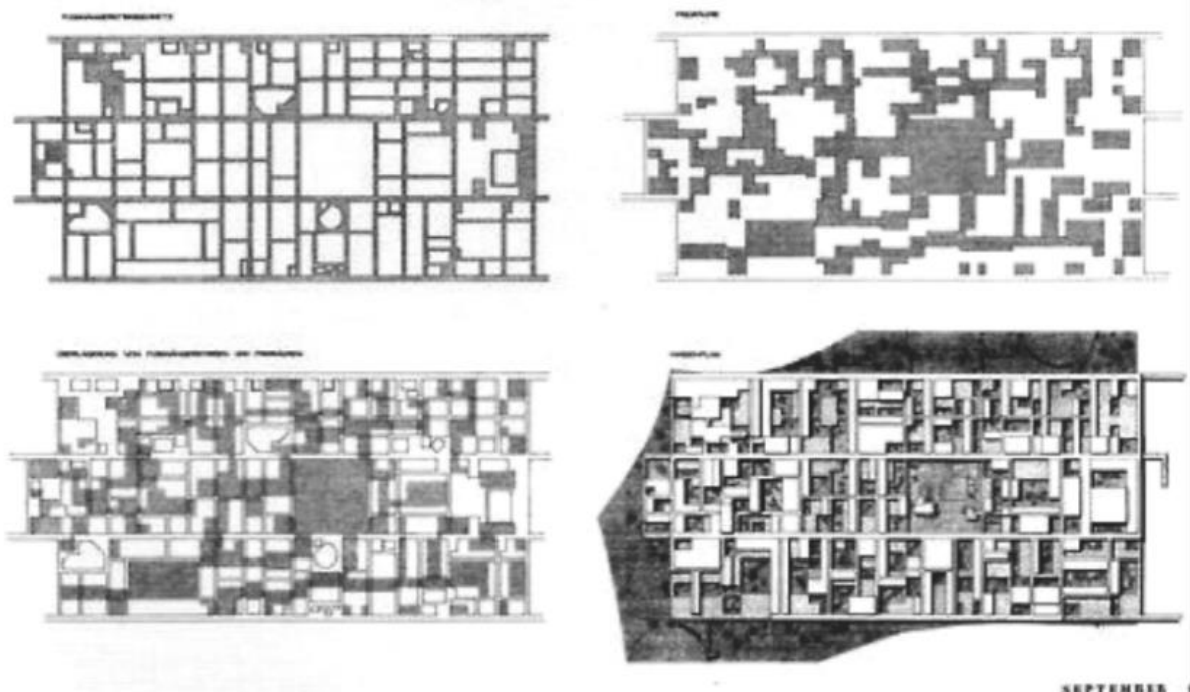

Figura 8 - Concurso da Universidade de Berlim, Candillis-Josic-Woods. O desenho superior esquerdo mostra a distribuição de pátios ao longo das ruas principais. Kiem, 2008, p. 188.

do final da década de 1960, demonstram o avanço do ICC de Niemeyer e Lelé em quase uma década de pioneirismo em sua concepção. As alas do ICC se configuram como ruas internas cobertas, a exemplo das ruas que inspiraram os arquitetos alemães no projeto da FUB.

Candilis e Woods começaram a trabalhar juntos no Marrocos, entre 1951 a 1955 , e o conceito adotado também é reminiscente dos bazares de ruas e dos pátios que encontraram nas cidades do norte da África. De modo que a arquitetura mediterrânea também serviu de ideia formal para o projeto. Outro importante ponto de referência foi o conceito de espaço-tempo, desenvolvido nos anos 1920. Essa teoria foi importante para o Team-X, ao qual Candilis e Woods pertenciam (KIEM apud MAHLER, 2015, p. 164). 
Figura 9 - Universidade da Calábria, Cosenza, Itália, 1972, Gregotti e Martensson. Fonte: http://obviousmag.org/archives/2006/09/utopia_1.html.

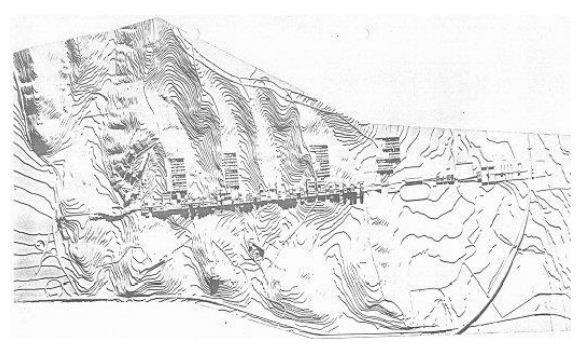

O partido do ICC remete a outras soluções de megaestruturas bem-sucedidas, não apenas em tramas. $\mathrm{O}$ caso da Universidade de Calábria (1972), originalmente projetada por Vittorio Gregotti e Dänen Martensson, na Itália, é um exemplo em que a megaestrutura linear mostrou-se adequada como solução de assentamento em um território de topografia bastante acidentada. A relação que se faz com o Minhocão é imediata, observando-se sua extensão.

O partido italiano optou pela construção do edifício ao longo de uma ponte suspensa, com 1,3 km de extensão, para tornar-se um elemento conector da região, transformar a paisagem e promover uma arquitetura de qualidade, com a urbanidade de uma rua interna. Como nas universidades britânicas e norte-americanas, os estudantes habitam blocos específicos, próximos à universidade. A estrutura, como um todo, está suspensa nos morros verdes do vilarejo de Arcavacata, a $10 \mathrm{~km}$ de Cosenza (GREGOTTI, 2010). No ICC, o partido em extensão teve a topografia favorável à criação de acessos transversais diretos ao rez do chão e ligações com o entorno nos pontos médios e extremidades, o que poderia estar comprometido no caso de outro contexto topográfico, como ocorre na UNICAL.

Outro exemplo de arquitetura institucional que remete ao ICC é o projeto de Paulo Mendes da Rocha para a Universidade de Vigo, em Pontevedra, na Espanha. Neste projeto, de 2004, o arquiteto e sua equipe optam por um partido baseado na axialidade e na extensão. O eixo principal oxigena o sistema de circulações, as unidades acadêmicas são edifícios que se plugam ao eixo principal, funcionando como uma espécie de mapa que direciona e organiza os espaços cobertos. Aqui, também, Paulo e equipe optaram pela liberação da paisagem e o tratamento das fachadas para o conforto ambiental ao clima rigoroso da região.

Paulo Mendes da Rocha foi convidado, em 2004, para desenhar a ampliação do setor de ciências tecnológicas da Universidade de Vigo, na Espanha. Idealizada com a colaboração do escritório paulistano MMBB e do espanhol Alfonso Penela Fernandez. A proposta evoluiu para a concepção do plano diretor da unidade Lagoas-Marcosende, na cidade de Pontevedra. O projeto é estruturado por nova lógica de transposição do terreno e pela ordenada provisão 


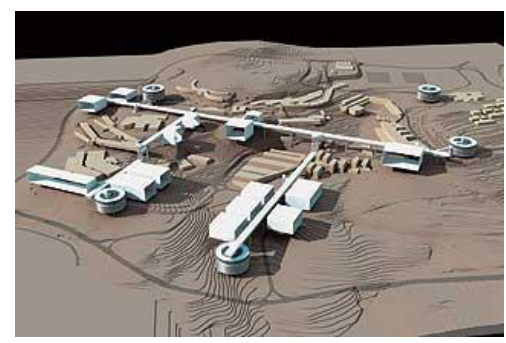

da infraestrutura necessária ao funcionamento das edificações atuais e futuras. [...] O campus, já consolidado, com quase 15 anos de existência, possui grande demanda de expansão. A equipe detectou como problemático o princípio passivo de ocupação do lote acidentado: a construção de edifícios segundo ofertas parciais da topografia, privilegiando a ocupação de áreas isoladas em decorrência de movimentações de terra. (http://www.arcoweb. com.br/arquitetura/paulo-mendes-da-rocha-mmbb-arquitetos-e-alfonso-penela-fernandez) Acesso em 20/07/2013.

Comparado ao ICC, e guardadas as proporções, a obra de Pontevedra cumpre seu papel de estabelecer a lógica de conexões entre as unidades do sistema. Por outro lado, sua relação com a paisagem torna-se indireta, ao contrário do exemplo brasileiro que se comunica diretamente com o exterior pelos seus pontos de acessos.

A incorporação do elemento condutor nos moldes de "ruas internas" ao projeto do ICC, talvez seja o principal responsável e catalisador de urbanidade no campus, como será posteriormente comentado.

O pensamento sistêmico para partidos de universidades foi adotado por

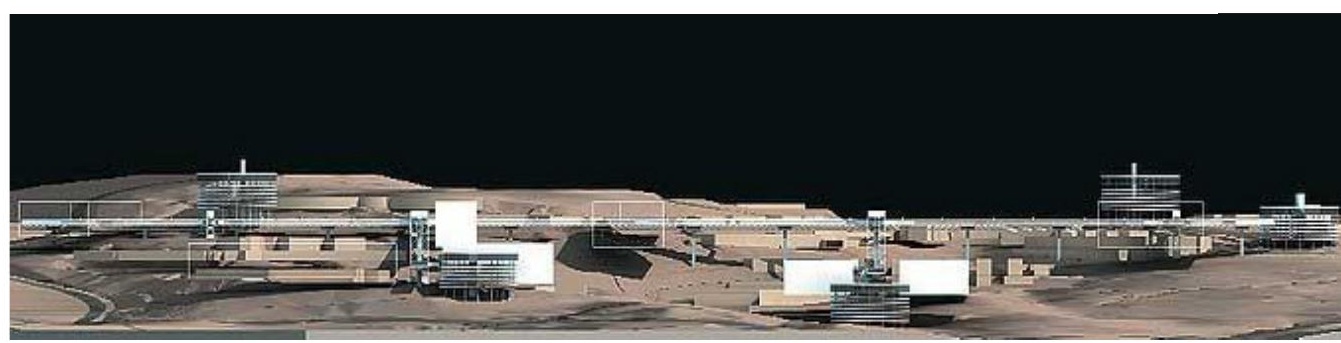

várias universidades federais brasileiras com partidos compostos por pavilhões articulados, como a Universidade Federal de Minas Gerais, UFMG (1969-); a Universidade Federal de Goiás, UFG (1972-); a Universidade Feral do Amazonas, UFAM (1973-80), dentre outras.

O modelo de análise estrutural proposto para a UFMG parte da conceituação da universidade como um sistema a ser considerado na sua totalidade, mas numa perspectiva evolutiva, isto é, uma série de totalidades abertas umas sobre as outras. Assim, não haveria uma estrutura universitária sincrônica, mas um processo de estruturação (diacrônico) que implicaria um processo de desestruturação de estruturas preexistentes. Enquanto sistema gerador, a Universidade seria uma combinatória de unidades que não visava a uma síntese, mas abrigava diversas possibilidades estruturais (MALARD, 2012, p. 139).

A relação de um edifício de universidade com a paisagem é uma questão relevante a ser considerada. A dispersão no verde é "um dos aspectos mais tradicionais da estrutura do conceito de campus" (MACIEL e MALARD, 2012, p. 64).
Figura 10 - Maquete física e conceitual do projeto da Universidade de Pontevedra, Espanha. Projeto de Paulo Mendes da Rocha, MMBB e Alfonso Penela Fernandez, 2006. Fonte: www. arcoweb.com.br/arquitetura/ paulo-mendes-da-rocha-mmbb-arquitetos-e-alfonso-penela-fernandez-plano-diretor-18-07-2006.

Figura 11 - Maquete eletrônica da via principal. Fonte: www. arcoweb.com.br/arquitetura/ paulo-mendes-da-rocha-mmbb-arquitetos-e-alfonso-penela-fernandez-plano-diretor-18-07-2006. 
156

Figura 12 - Maquete do Sistema Básico UFMG. Em cores, a partir do primeiro sistema Escola e Hospital Veterinário (vermelho); Instituto de Ciências Biológicas (verde); Centro Pedagógico (amarelo); Escola de Belas Artes (azul). Fonte: Maciel, 2011.

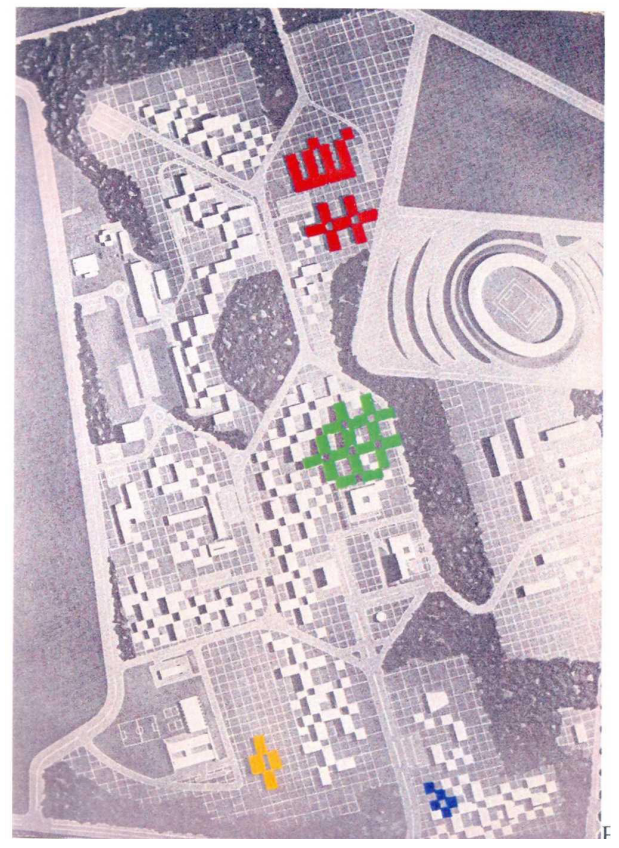

O exemplo do campus Pampulha da UFMG se mostra como uma solução eficiente em diferentes aspectos. Esse modelo, denominado por muitos como "centro universitário", é diferente do campus afastado, e do "complexo universitário", imerso no núcleo urbano. Segundo Maciel (2012), esta solução é eficaz porque não aceita o problema do isolamento e da autonomia, considerando as conurbações.

O novo modelo tende a se configurar como um sistema de organização aberto, coerente com o conjunto de princípios e concepções, em cuja direção tende a renovação do ensino superior [...]. Do ponto de vista morfológico, o modelo se configura como um sistema flexível de formas capazes de seguir o moto-contínuo dos sistemas de organização, sem nunca per- der a identidade no curso da mutação (MACIEL apud MAHLER, 2015, p. 180-181).

Comparativamente a esse exemplo de organização espacial em trama aberta, o partido do ICC, enquanto articulador do campus da UnB é menos permeável ao exterior que a UFMG, já que sua configuração, isolada dos demais edifícios, impossibilita o crescimento integrado. O ICC é estruturador em si e na travessia do campus, nos trechos em que é utilizado como rua interna, sem, contudo, promover outras conexões transversais, a não ser na porção central dos acessos.

Na UFMG, o brutalismo também é identificado, mostrando-se, mais uma vez, como uma linguagem adequada ao caráter da arquitetura institucional, de 
longa permanência temporal e que atende à lógica de organização das universidades brasileiras.

Para além da análise dos aspectos formais, funcionais e construtivos, que conduzem à reflexão do edifício em si mesmo, ou da comparação com edifícios de partidos similares, outros parâmetros podem ser acrescentados nessa discussão: os paradigmas da formalidade e urbanidade. Para isso, o aporte da Teoria da Sintaxe Espacial (SE) será utilizado, sem a finalidade de qualquer aprofundamento ou julgamento sobre a mesma.

A teoria sintática (HILLIER e HANSON, 1984) parte da premissa de que "a organização espacial humana, seja na forma de assentamentos ou de edifícios, é o estabelecimento de padrões de relações compostas por barreiras e permeabilidades de diversos tipos" Os paradigmas da formalidade e urbanidade são conceitos abordados pelos autores como tendências polares que podem ser observadas em manifestações ao longo da história das formas arquitetônicas e urbanísticas, que pressupõe comunicar ideias relativas ao espaço físico, por meio dos padrões espaciais e ideias relativas à vida espacial e à vida social (HOLANDA, 2004, p.114).

$\mathrm{Na} \mathrm{SE}$ “a organização espacial humana, [...] é o estabelecimento de padrões de relações compostas por barreiras e permeabilidades de diversos tipos, registrados a partir do movimento de pedestres sobre o chão.” As barreiras podem ser constituídas por edifícios isolados e por elementos como “jardins, piscinas, desníveis ou qualquer tipo de obstáculo que restrinja o movimento." (HOLANDA, 2003, p. 96).

Os espaços abertos são, assim, decompostos em convexos e axiais. Ao caminhar pelo espaço aberto da cidade sempre cruzamos transições invisíveis entre dois lugares (dois espaços convexos) ao dobrarmos uma esquina ou ao adentrarmos a uma praça. Um espaço convexo corresponde a um "lugar" em pequena escala; um pequeno trecho de uma rua, uma praça. As fronteiras invisíveis entre esses lugares transformam-se em pequenos segmentos de linha reta no mapa de convexidade. A técnica de convexidade decompõe o sistema de espaços abertos de uma cidade em unidades de duas dimensões. Em SE o espaço "fechado" não é necessariamente coberto. Essas categorias permitem, através de abstrações, inferir e analisar os espaços, investigando as consequências de sua forma no espaço.

Num extremo, o paradigma da $u r b a-$ nidade refere-se à cidade ou ao edifício como realidade física. Etimologicamente, a palavra remete à qualidade de cortesia, da ideia de urbanitas, e cuja configuração possibilita a manifestação das relações, permeável à convivência, tendo configuração espacial atrativa para os usuários, por vezes agregada de magnetos que catalisam encontros $^{4}$ (sistemas multifuncionais).

No extremo oposto, o paradigma da formalidade refere-se aos limites exteriores da matéria, no âmbito configuracional. Neste sentido, o que é "formal" tem o "urbano" como antítese, ou seja, dificulta
${ }^{4}$ Para JACOBS (1961), a urbanidade está diretamente relacionada à mistura de usos em um espaço urbano. A autora critica o urbanismo moderno e sua proposta de zoneamentos, que segregam as atividades. 
${ }^{5}$ HOLANDA (2002), analisa a formalidade nos assentamentos Maias e na Esplanada dos Ministérios de Brasília, por suas grandes dimensões, sua forma de assentamento monumental sobre terraplenos, pela distribuição e dispersão dos edifícios, dentre outros parâmetros.

Figura 13 - Mapa axial das calçadas. Fonte: RODRIGUEZ, 2007. os acessos, é dotado de barreiras de diversas naturezas (topográficas, físicas, recuos, etc.) causando impermeabilidades às relações através de quaisquer elementos, incluindo o próprio espaço em si. ${ }^{5}$ Dessa maneira, prevalece a maximização do espaço aberto sobre a área total do assentamento, já que o fator distância dificulta o sistema de encontros. As outras variáveis, totalizando nove exploradas pelo autor, estão citadas abaixo:

\section{[...] além do maior espaço convexo} médio; menor número de entradas

\begin{abstract}
por espaço convexo; maior percentual de espaços cegos; estrutura axial extremamente rasa ou profunda; baixas medidas de inteligibilidade; núcleos integradores ora no miolo ora na periferia do sistema (HOLANDA, 2002, p. 126).
\end{abstract}

O ICC participa das duas polaridades. Sua urbanidade é comprovada, também na SE, no mapa de integração, um dos parâmetros que permitem inferir sobre a urbanidade, a partir da alta utilização do espaço, como ilustra o diagrama abaixo:

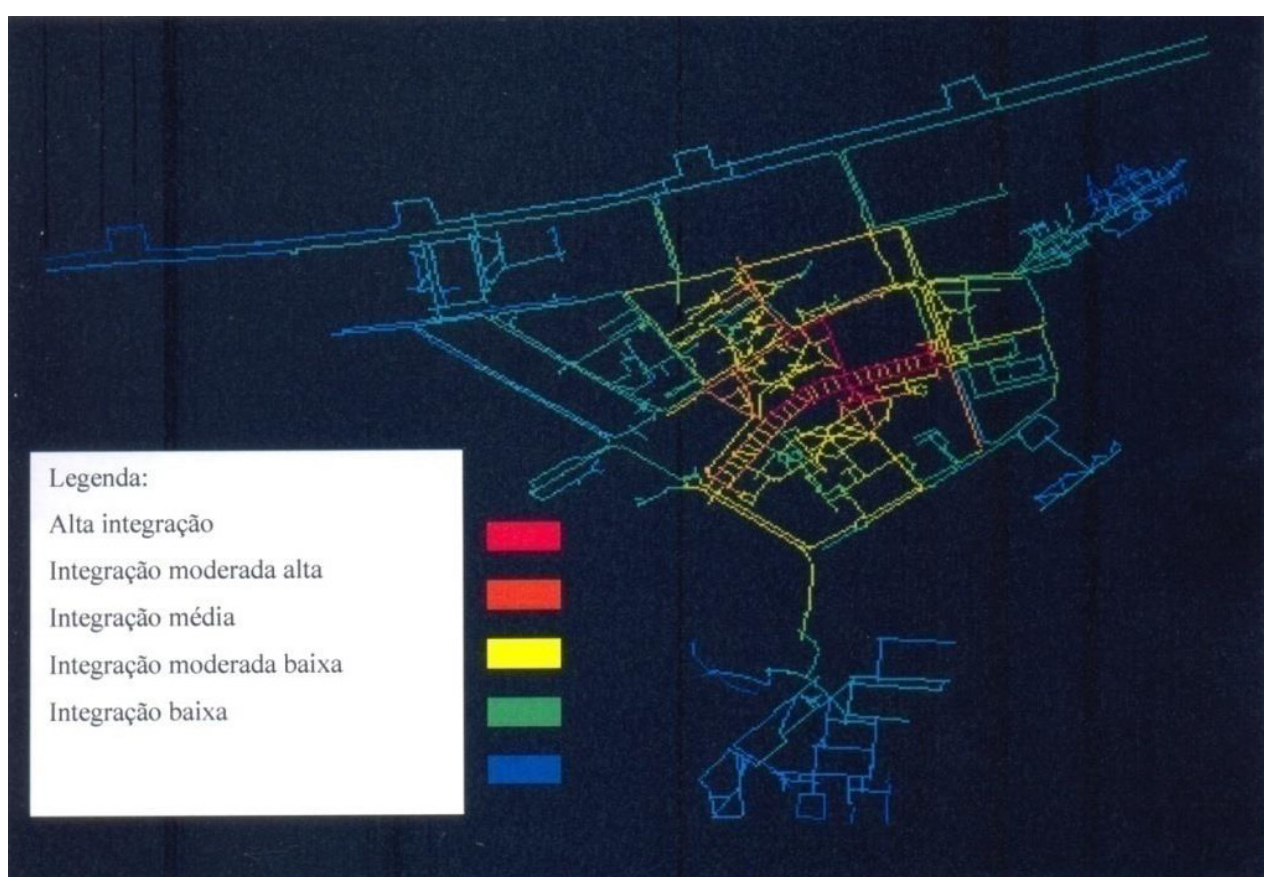

Outros atributos, de natureza simbólica, amplificam o escopo da análise do ICC, possibilitando o aprofundamento de discussões sobre o tema, como por exemplo, através da investigação de sua linguagem gráfica, que atua pela re- petição através da marca institucional (STRUNCK, 1989).

A marca institucional da UnB é de autoria do pernambucano Aloisio Magalhães, artista gráfico, designer e programador visual, iniciada no ano de 1963. 


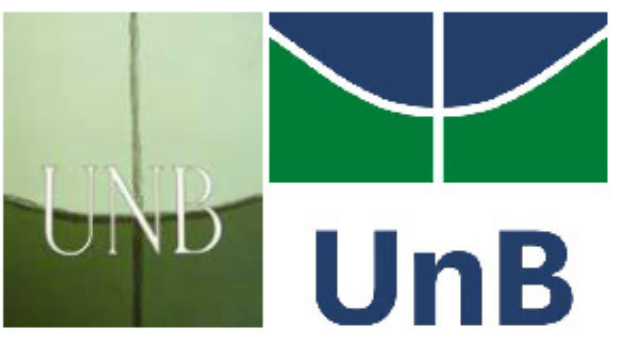

A marca, composta de logotipo (texto) e símbolo (imagem) (STRUNCK, 1989),

"[...] é distribuída em suportes físicos no campus, em impressos e em suportes digitais, "o símbolo é consideravelmente conhecido, não só pela comunidade universitária, mas também pelo público externo. É o mais forte elemento da Identidade Visual da UnB desde sua fundação. "Acredita-se que Aloisio Magalhães tenha utilizado a ilustração de capa do Plano Orientador como referência" (www.marca.unb.br/historico.php. Acesso em 23 de julho de 2013).

Ao mesmo tempo em que o símbolo remete aos fluxos do Plano Piloto, dividido pelas asas, os quadrantes e o Eixo Monumental, identifica, também, um microcosmo especializado de Brasília, o campus da sua universidade. Aloisio, ao fazer a opção por este partido gráfico, fez referência à modernidade, adotando sua iconografia: o próprio elemento gerador de Brasília.

Além deste, o exemplo da marca da Faculdade de Arquitetura e Urbanismo da UnB, optou pela referência direta ao ICC. Desta vez, seus pórticos repeti-

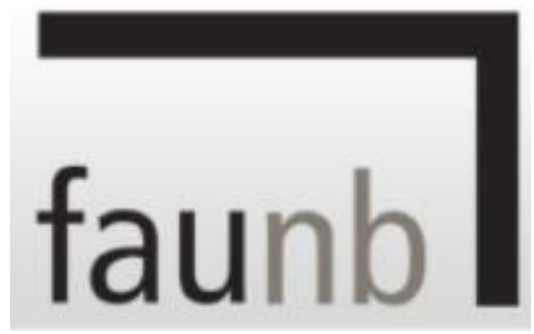

tivos foram eleitos como elemento de síntese visual, como alusão à estrutura construtiva do edifício. A proporção do desenho adotado pelo autor é compatível com as proporções dos pórticos, vistos nos cortes transversais do projeto do ICC. A parte aberta (interrompida) da moldura sugere a posição do jardim interno e da circulação.

Os símbolos institucionais aqui mencionados reportam diretamente à ideia do espaço construído da cidade e do edifício, respectivamente. Como um abrigo, os pórticos na marca da FAU-UnB "delimitam" seu espaço, funcionando como uma espécie de moldura e respeitando, ainda, a linguagem visual objetiva, adotada na marca da universidade. Ambos sã eficazes à comunicação visual, com adequação aos meios físicos e digitais de reprodução e veiculação da marca. Ambos confirmam, finalmente, a imagem forte da espacialidade do ICC.

\section{CONSIDERAÇÕES FINAIS}

O ICC confere identidade à UnB, pela sua proposta de edifício único para congregar os institutos. A instituição,
Figuras 14 e 15 - Capa do Plano de Orientação da Universidade de Brasília e Marca da Universidade de Brasília - Assinatura Visual colorida vertical. Fonte: www. marca.unb.br.

Figura 16 - Marca da FAU-UnB. Assinatura horizontal parcial. Autoria de Joe Rodrigues, 2008-09. Fonte: www.fau.unb.br. 
como dito é identificada pelo "Minhocão”, que é um exemplo da arquitetura moderna brasileira brutalista, inovador em relação a várias universidades com partidos em sistemas - em tramas, lineares, radio-concêntricos, etc. - , partidos que viriam a proliferar na década seguinte em projetos de universidades como megestruturas. A inovação, urbanidade, legibilidade e identidade do ICC são, portanto, comprovadas.

As circulações ao longo das alas consistem em um grande benefício para o projeto, pois articulam os percursos em direção à Reitoria, Biblioteca, ao Restaurante ou ao Centro de Vivência e adjacências, estimulando os encontros espontâneos. A forma linear da extensão do edifício sugere estas circulações, induzindo este tipo de utilização, funcionando como uma grande rua interna para cada ala longitudinal, ao longo da qual os acessos transversais se cruzam. A ampla utilização do edifício, principalmente nestas circulações foi demonstrada por meio da Sintaxe Espacial.

Esses parâmetros permitiram inferir sobre a urbanidade no ICC no tempo presente. Por outro lado, seria improvável que um edifício que abrigasse tantas unidades acadêmicas não tivesse um grande afluxo de pessoas. O edifício é bastante elogiado por visitantes estrangeiros, que o perceberam como um grande sistema espacial: uma grande rua.

Por outro lado, a forma do ICC é limitadora, nos sentidos transversal e longitudinal, já que a asa norte termina em uma ponta de quadra, sem possibilidade de expansão. No partido em trama da UFMG, as estruturas ambientais pavilhonares e em estrado são passíveis de crescimento, portanto adequadas à dimâmica das temporalidades, inerente às universidades. Por esse prisma, pode-se dizer que o partido do ICC poderia ter sido diferentemente explorado, para atender às questões de infraestrutura, crescimento, superação da funcionalidade e construção da paisagem.

Nestes aspectos, o edifício se aproxima do paradigma da formalidade. Sua disposição não promove encontros quanto o sistema em rede, a não ser a partir e por causa dos longos percursos.

Apesar destas lacunas, a potência do ICC é inquestionável, no bojo de sua formalidade e de sua imagem. A ligação com
Figura 17 - Imagem sugestiva da ocupação transversal. Fonte: Rodriguez, 2007.

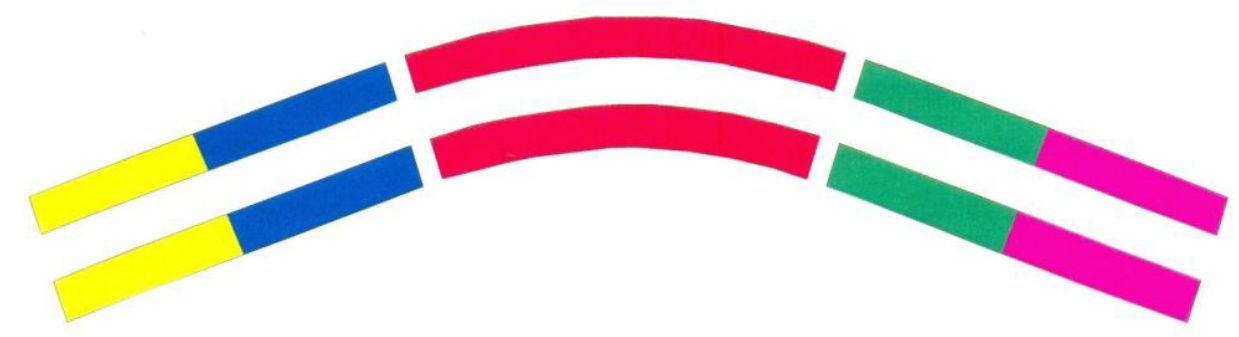


a Praça Central é direta, mas a relação da megaestrutura com os demais edifícios que margeiam a L4 é dificultada por uma grande barreira: o grande espaço destinado aos estacionamentos.

$O$ conceito de "universidade moderna" - contribuição de Wilhelm Von Humboldt, na Universidade de Berlim, na Alemanha, por volta de 1810 -- foi a inserção da pesquisa e produção científica como um pilar fundamental à instituição (CASTILHO, 2008), questionando o conhecimento enciclopédico e operando com a possibilidade do conhecimento em permanente construção. Os desafios das universidades do século XXI são tantos quanto as lutas, desafios e as tensões de nossa sociedade, como o esgotamento de recursos naturais, as consequências das revoluções tecnológicas, as lutas das minorias, o multiculturalismo, a diversidade e a inclusão social e física, através da acessibilidade (design universal), dentre outros. No que tange ao multiculturalismo, não resta dúvida que o ICC se apresenta adequado, proporcionando convívio por proximidade às diferentes áreas de conhecimento. $\mathrm{A}$ diversidade está aí contemplada, porém a inclusão física, no sentido de integração aos demais espaços é dificultada por sua "formalidade", devido à sua morfologia limitadora de espaços no sentido transversal. Quanto à acessibilidade, esse critério também não se encontra por todo solucionado, pois o edifício possui escadas íngremes de acesso aos subsolos e mezaninos, devido à ocupação longitudinal do edifício, em contraponto ao que havia sido imaginado por Nie- meyer, ao sugerir ocupações transversais. Cápsulas e elevadores precisaram ser incorporados para a solução do problema da circulação vertical acessível devido à adaptação dos subsolos ao uso de ambientes acadêmicos.

As universidades no modelo de campus enfrentam, por suas grandes distâncias a desurbanidade, por operarem em diferentes escalas, o que dificulta a leitura dos espaços e interfere nas relações.

A complexidade dos programas para universidades demandam uma leitura eficiente dos espaços e orientação para atender o grande afluxo de usuários. Nesse quesito, o projeto de Mendes da Rocha parece se oferecer como o mapa em escala natural e autoexplicativo das edificações, que se distribuem em seu terreno. Não apenas pelo critério de configuração espacial, o partido de Vigo oferece outras vantagens. Como o próprio ICC, seu percurso é feito nos moldes de uma rua interna, proporcionando conforto climático às diferentes situações: iluminação noturna, sombreamento diurno, proteção contra intempéries.

$\mathrm{O}$ brutalismo se faz presente no partido arquitetônico do ICC, no uso de concreto aparente e no despojamento de acabamentos, adequado a projetos de numerosas universidades, atendendo às limitações orçamentárias. A utilização das paredes de seus interiores como espaços de suporte para manifestações espontâneas das comunidades acadêmicas, bem como para a exposição de informações são necessárias nas instituições de ensino, 
sempre com alta carga de poluição visual. $O$ passeio pelo ICC ilustra os efeitos da pós-ocupação das diferentes áreas de conhecimento que abriga e o resultado da apropriação desses espaços, garantindo que as inúmeras identidades se manifestem. Cada trecho do ICC tem o espírito de seus habitantes, sua própria "cultura".

Ainda inacabado até o presente, o Minhocão se tornou o elemento organizador do campus da UnB, a partir do qual foram distribuídas as demais edificações. O campus da UnB, por sua vez, tem grande qualidade arquitetônica e urbanística, apesar do tímido planejamento. E, mesmo sem ignorar seus incontáveis problemas, não deixa de ser emocionante percorrer a heróica extensão e ser surpreendido com a qualidade de alguns de seus espaços e com a discrição da presença do ICC na paisagem do campus.

\section{REFERÊNCIAS BIBLIOGRÁFICAS}

ALMEIDA, Jaime G. de. Campus do Milagre. Dissertação de Mestrado IAU-UnB, 1983.

BUSTOS ROMERO, Marta A. Universidade nos Quatro Cantos - Planos Diretores Urbanísticos dos Campi da Universidade de Brasília - UnB 50 anos. Brasília: Universidade de Brasília, Faculdade de Arquitetura e Urbanismo, 2012.

CASTILHO, Fausto. O conceito de universidade no projeto da UNICAMP. Campinas: Ed. Unicamp, 2008.

CASTOR, Ricardo. S. Dimensão estética da obra de Oscar Niemeyer: o caso do Instituto Central de Ciências da UnB. Dissertação de mestrado. Brasília: PPG-FAU-UnB, 2004.

FICHER, Sylvia (org.). Instituto Central de Ciências 1963/1971. Brasília: UnB, 2001.

FICHER, S., ACAYABA, Marlene M. Arquitetura moderna brasileira. São Paulo: Projeto, 1982.

FRAMPTON, Kenneth. Modern architecture: a critical history. New York: Oxford University Press, 1980.

GOROVITZ, Matheus. Brasília, uma questão de escala. São Paulo: Projeto, 1985.

GREGOTTI, Vittorio. Território da Arquitetura. São Paulo: Ed. Perspectiva, 2010, 3a edição.

HILLIER, Bill; HANSON, Julienne. The social logic of space. Cambridge: Cambridge University Press, 1984.

HOLANDA, Frederico de. O espaço de exceção. Brasília: Editora Universidade de Brasília, 2002. (org.). Arquitetura E Urbanidade. São Paulo: ProEditores Associados Ltda, 2003a.

JACOBS, Jane. Morte e Vida das grandes cidades. Ed. Martins Fontes. São Paulo, 2001.

MACIEL, Carlos A. O sistema básico da UFMG e seus precedentes: infraestrutura, crescimento, superação da função e construção da paisagem. Brasília: Anais do 9o Seminário Docomomo Brasil, 2011. 
MACIEL, Carlos A., MALARD, Maria Lúcia (orgs.). Territórios da universidade: Permanências e transformaçôes. Belo Horizonte: Editora UFMG, 2012.

MAGALHÃES, Aloisio. A herança do olhar. São Paulo: Senac, 2003.

MAHLER, Christine R. Territórios universitários: tempos, espaços e formas. Tese de Doutorado PPG-FAU-UnB. Brasília, 2015.

RODRIGUEZ, Milena. UnB e seu espaço social. Dissertação de Mestrado PPG-FAU UnB. Brasília: 2007.

SCHLEE, Andrey R. A Praça Maior da UnB. Brasília: Anais do 9o Seminário Docomomo Brasil, 2011.

(org.). Registro arquitetônico da Universidade de Brasília. Brasília: Editora Universidade de Brasília, 2014.

STRUNCK, Gilberto. Identidade Visual: a direção do olhar. São Paulo: Ed. Europa, 1989.

TURNER, Paul V. Campus: an american planning tradition. The MIT Press: Architectural History Foundation Book, 1995, (2nd. Paper edition).

\section{Sites visitados:}

www.unb.br. Acesso em 10/06/2013.

www.arcoweb.com.br/arquitetura/paulo-mendes-da-rocha-mmbb-arquitetos-e-alfonso-penela-fernandez-plano-diretor-18-07-2006. Acesso em 20/07/2013.

http://obviousmag.org/archives/2006/09/utopia_1.html. Acesso em 31/07/2013.

http://www.marca.unb.br/historico.php. Acesso em 28/07/2013.

Christine Ramos Mahler - Arquiteta e urbanista (PUC-GO, 1989), Mestrado em Gestão do Patrimônio Cultural (IGPA/UCG, 2004), Doutorado em Arquitetura e Urbanismo (UnB, 2015). Professora Adjunta da Universidade Federal de Goiás, e atuando também no Programa de Pós-Graduação em Projeto e Cidade.christinermahler@hotmail.com. 